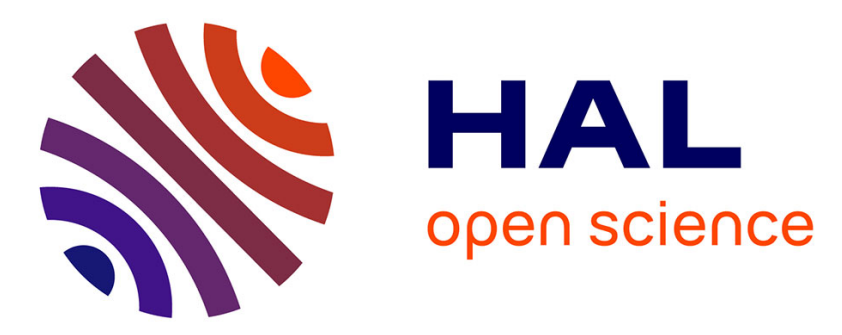

\title{
Remote detection of welds depth penetration by laser generated ultrasonics
}

D. Rochais, L. Paradis, F. Lepoutre

\section{To cite this version:}

D. Rochais, L. Paradis, F. Lepoutre. Remote detection of welds depth penetration by laser generated ultrasonics. Journal de Physique IV Proceedings, 1994, 04 (C7), pp.C7-693-C7-696. 10.1051/jp4:19947162 . jpa-00253222

\section{HAL Id: jpa-00253222 https://hal.science/jpa-00253222}

Submitted on 1 Jan 1994

HAL is a multi-disciplinary open access archive for the deposit and dissemination of scientific research documents, whether they are published or not. The documents may come from teaching and research institutions in France or abroad, or from public or private research centers.
L'archive ouverte pluridisciplinaire HAL, est destinée au dépôt et à la diffusion de documents scientifiques de niveau recherche, publiés ou non, émanant des établissements d'enseignement et de recherche français ou étrangers, des laboratoires publics ou privés. 


\title{
Remote detection of welds depth penetration by laser generated ultrasonics
}

D. Rochais, L. Paradis and F. Lepoutre*

CEA DAM, BP. I2, 91680 Bruyères-le-Châtel, France

* ONERA L3C, BP. 79, 92322 Châtillon, France

\begin{abstract}
This paper presents applications of the laser induced shear wave directivity pattern in the thermoelastic regime, to the detection and the in-depth profiling of overthickness and closed cracks perpendicular to the surface. Some results on academic samples and first measurements of actual depth profilings of welds are presented and discussed.
\end{abstract}

\section{INTRODUCTION}

Laser generated ultrasonics is an attractive non destructive testing and associated with an optical detection, it becomes a contactless system. The goal of our study is to detect and to measure, in the thermoelastic regime, overthicknesses and weld depth penetrations on 1 to $3 \mathrm{~mm}$ thick metallic samples.

\section{THEORETICAL BACKGROUND}

When a laser pulse irradiates a solid surface, a part of the incident energy is reflected off and a part is absorbed at the surface. The fast temperature rise localized near the surface involves a local thermal expansion of the material in which a strain field is developed. In the thermoelastic regime, this source, considered as a set of force dipoles tangential to the surface, generates bulk and surface waves. As it is well known, in such a regime, the conversion efficiency is much better for the shear waves than for the longitudinal waves.

We calculated the directivity function of the shear waves [1] in the far field at $5 \mathrm{MHz}$ for a duraluminum sample and a laser impact of $0.5 \mathrm{~mm}$ diameter. The experiment is performed on a halfcylindrical duraluminum sample of radius $50 \mathrm{~mm}$ which has its circumference constituted of 18 facets by steps of $10^{\circ}$. The detection is obtained with a contact piezo transducer (peak frequency: $5 \mathrm{MHz}$ ). Figure 1 shows a good agreement between calculations and experiment.

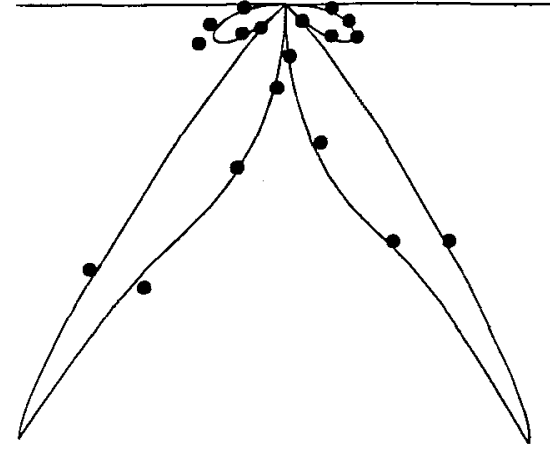

Fig.1 : Shear wave directivity pattern (- calculated, - experimental data ). 


\section{EXPERIMENTAL SET-UP}

\subsection{Thermoelastic generation}

The thermoelastic generation is achieved with a Q-switched Nd: YAG laser at a wavelength of $1.06 \mu \mathrm{m}$ and a pulse duration of $15 \mathrm{~ns}$. This pump beam is focused by a cylindrical lens into a line of height $8 \mathrm{~mm}$ and width $0.5 \mathrm{~mm}$. The energy of each laser pulse $(100 \mathrm{~mJ})$ is reduced to obtain the thermoelastic regime.

\subsection{Optical detection}

Elastic waves are detected by a Mach Zehnder heterodyne interferometer [2] able to measure the normal surface displacement (sensitivity : $10^{-4} \AA / \sqrt{ } \mathrm{Hz}$ on a mirrorlike sample) with a $20 \mathrm{MHz}$ bandpass electronic detection.

\section{OVERTHICKNESS DETECTION OF AN EQUATORIAL WELD}

The first application of the directivity pattern we consider is the overthickness detection of an equatorial weld. An academic cylindrical sample (fig.2) has been used to estimate the method sensitivity.

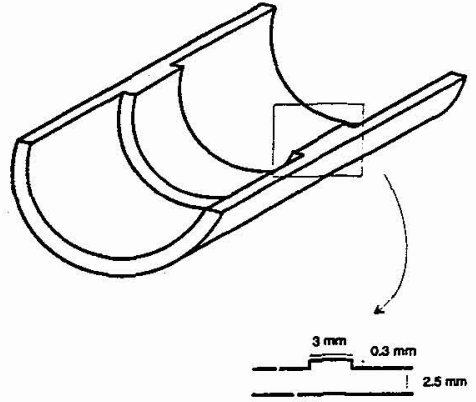

Fig.2 : Sample geometry.

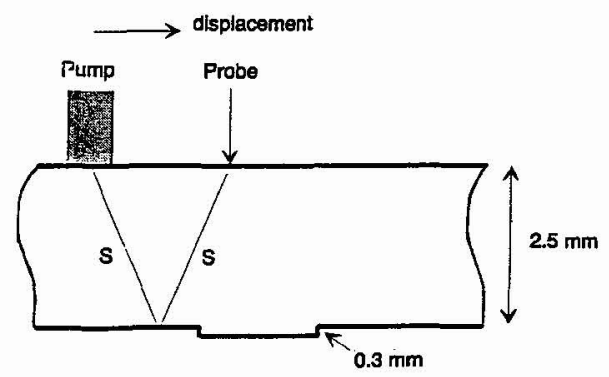

Fig.3 : Experimental configuration.

The distance between the pump and the probe beams, $4.5 \mathrm{~mm}$ here (fig.3), is given by the position of the maximum amplitude for the backwall reflected shear wave. Figure 4 gives the amplitude of the acoustic waves detected as the system pump-probe is moved along the surface .

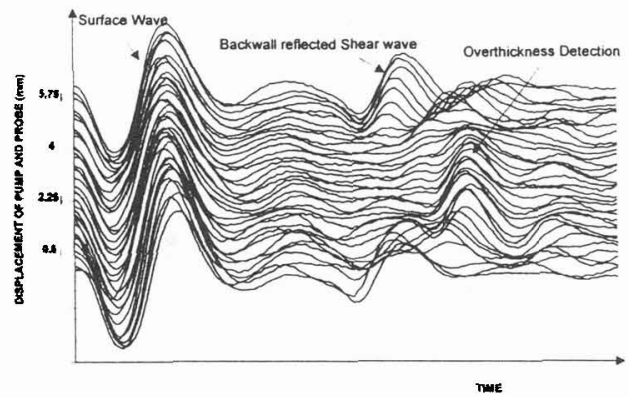

Fig.4 : Signal evolution with the displacement

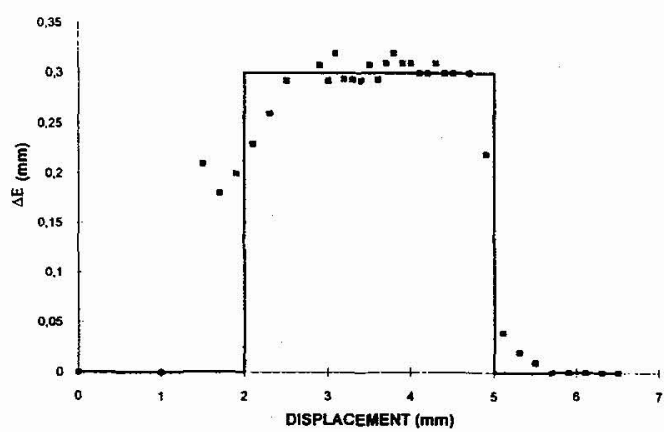

Fig.5 : Thickness variation with the displacement (- Experimental data, - Theoretical profile). 
We clearly notice the variation of the echo of the shear wave reflected off by the backwall when the wave encounters the overthickness. The corresponding thickness variation is presented in fig.5. The agreement between experimental data and theoretical profile is rather good, except where the diffraction effects occur.

This experiment points out two other results. First, we noticed a variation of the shear wave maximum amplitude position compared to the one given by the directivity pattern in the far field. We think that the optical detection made near the thermoelastic source is sensitive to near field phenomenon. Secondly, we observed, in the acoustic pulse, a frequency distribution lower than the one theoretically expected. It has been shown [3] that "the diffraction by the line source increases the impulse duration in the same way whatever is the observation direction in the bisecting plane". This theory seems to be the explanation of our observation.

\section{DETECTION OF WELDS DEPTH PENETRATION}

For this second application, we prepared duraluminum plates ( $3 \mathrm{~mm}$ thick) partly cut on one of their faces and used to calibrate experiments.

The pulse-echo configuration is described in figure 6 . The symmetry property of the directivity pattern is very useful to locate the vertical interface. Then, the system pump-probe beams moves on the surface.

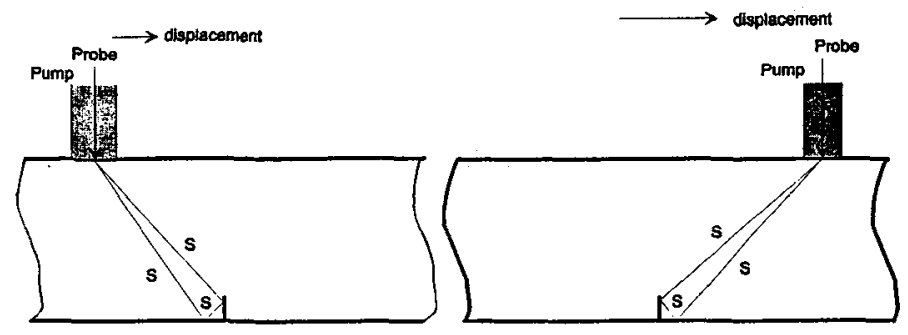

Fig.6 : Pulse-echo configuration to detect the "corner effect".

The time delay in the echo during the displacement for a $30 \mu \mathrm{m}$ notch shown in figure 7 is used in figure 8 to reconstruct the position of the vertical defect.

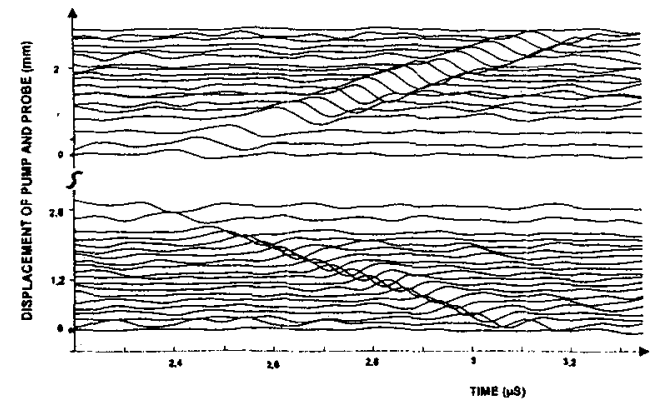

Fig.7 : Signal evolution with the displacement.

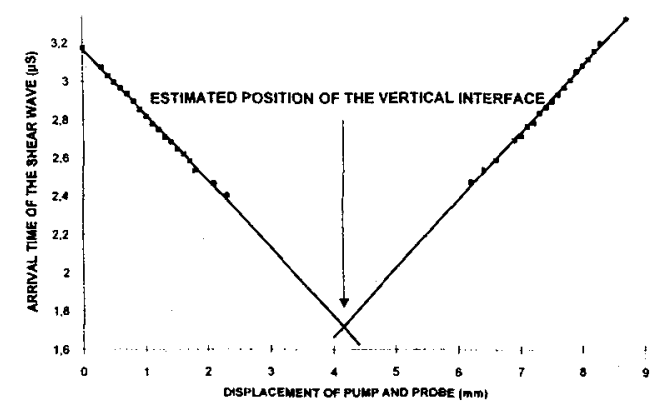

Fig.8: Variation of the shear wave arrival times (- Experimental data, - Linear regression).

A plane wave-front assumption near the vertical interface leads to a simple relation between the time delay $\Delta \mathrm{t}$, the angle of propagation $\alpha$, the pump-probe position $\Delta \mathrm{x}$ and the shear wave velocity $\mathrm{V}$ :

$$
\Delta \mathrm{t}=2 \cdot \Delta \mathrm{x} \cdot \operatorname{Sin} \alpha / \mathrm{V}
$$

For this plate, we find $\alpha \cong 32^{\circ}(\mathrm{V}=3100 \mathrm{~m} / \mathrm{s})$. This value is in good agreement with the shear wave maximum amplitude position given by the theoretical directivity pattern in the far field - about $30^{\circ}$. 
Figure 9 presents the shear wave amplitude variation with the displacement for 3 different notch heights. The maximum amplitude is a function of the vertical interface height, but the results obtained show there is not a proportional relation between the amplitude and the notch height.

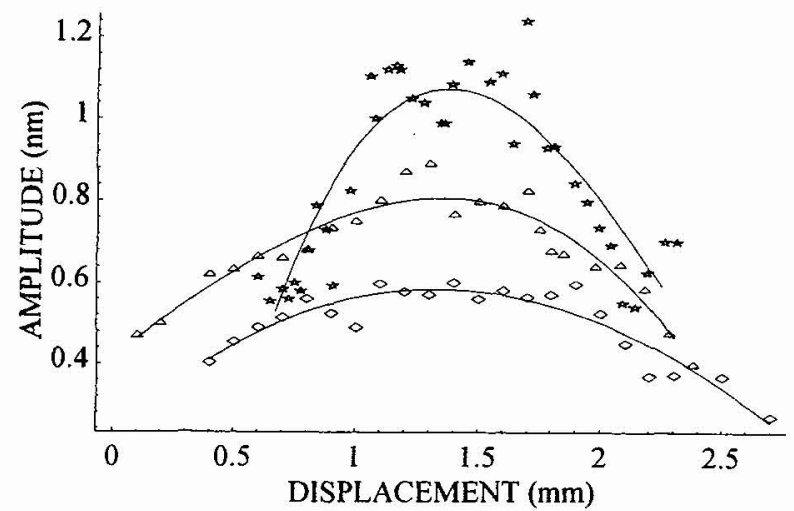

Fig.9 : Amplitude variation with the displacement for 3 notch heights $(30 \mu \mathrm{m} \diamond, 200 \mu \mathrm{m} \diamond, 500 \mu \mathrm{m} *)$.

Finally, we made measurements of depth penetrations of actual welds (see fig.10). The signal vs displacement (fig.11) shows that the detection on the welded zone is perturbed by the weld but is still detectable.

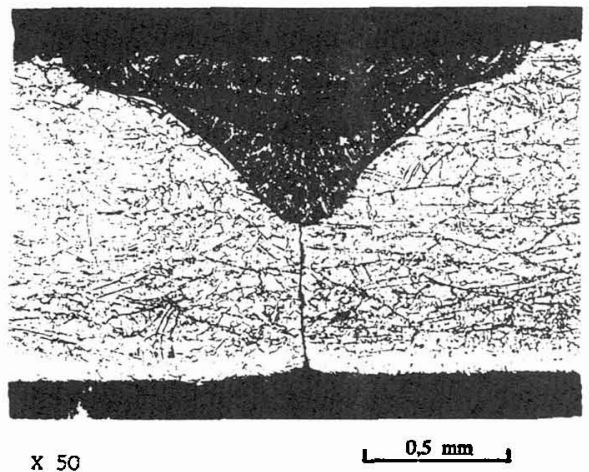

Fig.10 : Optical micrograph of weld.

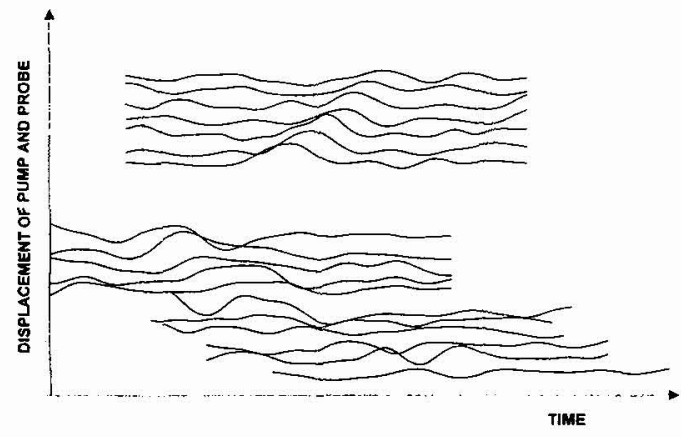

Fig.11 : Signal evolution vs time with the displacement

\section{CONCLUSION}

The remote generation and detection is well suited to the control of small curved parts for which classical ultrasonic testings (contact or immersion techniques) are not easy. We point out two applications of the shear wave directivity pattern. The first one could allow in a near future to draw up thickness profiles. The second one is very sensitive to vertical interfaces and allows to detect and locate vertical cracks.

At last, some improvements of the interferometer are under consideration. The use of a beam expander before the focused lens, thus reducing the spot size and increasing the speckle size, will involve better performance with rough surface. The Helium-Neon system substitution by a diode-pumped Yag (power $\cong 100 \mathrm{~mW}$ ) frequency doubled at a wavelength of $0.532 \mu \mathrm{m}$ will improve sensitivity.

\section{References:}

[1] G.F. Miller and H. Pursey, Proceedings of the Royal Society, London, Vol. A223, 1954.

[2] D. Royer and E. Dieulesaint, Ultrasonics Symposium, 1986.

[3] M.H. Noroy, D. Royer and M. Fink, J. Acoust. Soc. Am. 94 (4), October 1993. 